\title{
Prey selection by the copepod Diacyclops thomasi*
}

\author{
Richard S. Stemberger** \\ Great Lakes Research Division, The University of Michigan, Ann Arbor, MI 48109, USA
}

Summary. 1. Adult females of the predaceous copepod, Diacyclops thomasi, consistently selected for the soft-bodied rotifers Synchaeta pectinata, Polyarthra major and $P$. remata when presented various combinations of 8 rotifer species and 2 crustacean species as prey. Diacyclops did not select for other small, soft-bodied rotifers such as $P$. vulgaris and Ascomorpha ecaudis and, for loricate species such as Keratella cochlearis, $K$. crassa and for large soft-bodied adult Asplanchna priodonta. The small cladocerans, Bosmina longirostris and Chydorus sphaericus also were resistant to predation by this copepod.

2. Increased hunger in Diacyclops increased the clearance rates on both vulnerable and Diacyclops-resistant prey but did not greatly increase mortality of resistant prey relative to vulnerable prey. Sated Diacyclops preferred small, vulnerable prey like $P$. major over larger-bodied Synchaeta. This effect may be attributed to limited gut space when food is abundant.

3. When Diacyclops was presented different relative proportions of Keratella and Synchaeta at a constant total prey density (500 prey/L), it selected Synchaeta over Keratella in all trial proportions. However, Diacyclops selected more strongly for Keratella (but at a much lower clearance rate than for Synchaeta) when the relative abundance of this predator-resistant species was greatest. These results support optimal foraging in this predator.

4. Predator-prey interactions of the kind reported in this study can help identify important food web pathways and can be used to interpret predator-mediated changes in zooplankton communities in nature.

Invertebrate predators selectively modify zooplankton communities. Prey selection is influenced not only by a variety of behavioral and morphological features of the prey such as size, shape, escape responses and taste (Pastorok 1980; Riessen 1980; Williamson 1980; Kerfoot 1977, 1982; Li and Li 1979) but also by predator hunger (Pastorok 1981). The visibility of prey to visually hunting predators also may influence selection (O'Brien et al. 1979; Zaret and Ker-

\footnotetext{
* This study was partially supported by NOAA contract NA81RAH00003 to J.A. Bowers, The University of Michigan. Contribution number 408 Great Lakes Research Division, The University of Michigan

* Present address: Dartmouth College, Department of Biological Sciences, Hanover, N.H. 03755
}

foot 1975; Zaret 1972). Unlike crustacean zooplankton, rotifers are relatively immune to visually feeding fish predators because of their small size (Hrbáček 1962). However, seasonal predation by fish larvae (Siefert 1972; Duncan 1983) and by pelagic filter-feeding fish (Norden 1968; Drenner et al. 1982; Duncan 1984) may have a strong selective influence on limnetic rotifer communities. Nonetheless, most anti-predator adaptations of rotifers appear to be directed against small, tactile-orienting invertebrate predators.

Defensive adaptations of prey increase the time it takes a predator to complete the predation sequence. This is accomplished by interrupting specific steps which lead to ingestion such as recognition, pursuit, attack, capture, handling, and ingestion (Holling 1966; Kerfoot 1978). For example, posterior-spined Keratella cochlearis are difficult for cyclopoid and rotifer predators (Asplanchna) to manipulate once this prey is captured. These prey increase the predator's handling time or increase the rate of rejection after capture (Stemberger and Gilbert 1984). Large, turgid-bodied forms like Asplanchna are difficult for some small, predaceous cyclopoids to capture (Gilbert and Williamson 1978; Williamson 1983). Soft-bodied Filinia, Polyarthra and Hexarthra may avoid predators with the rapid movement of their spine-like or paddle-like appendages (Gilbert and Williamson 1978; Lewis 1977). These latter species increase the pursuit time or effectively decrease the encounter rate. As a result of these processes, predator-adapted prey are removed from the environment at a lower rate than prey which do not interfere with the predation sequence. The pattern of predation mortality which results forms the basis of selective predation and ultimately affects the species structure of plankton communities.

In this paper, I present results from a variety of experiments designed to test selection of the common cyclopoid copepod, Diacyclops thomasi, for rotifer and crustacean prey under different configurations of prey choice, prey proportion and density, and predator hunger level. Knowledge of this predator's prey preferences from laboratory studies can be used to identify important trophic links in the plankton and also to interpret temporal changes in rotifer communities in nature (Stemberger and Evans 1984).

\section{Methods}

Diacyclops thomasi (Forbes) (=Cyclops bicuspidatus thomasi) was collected from Lake Michigan in June, 1981, 


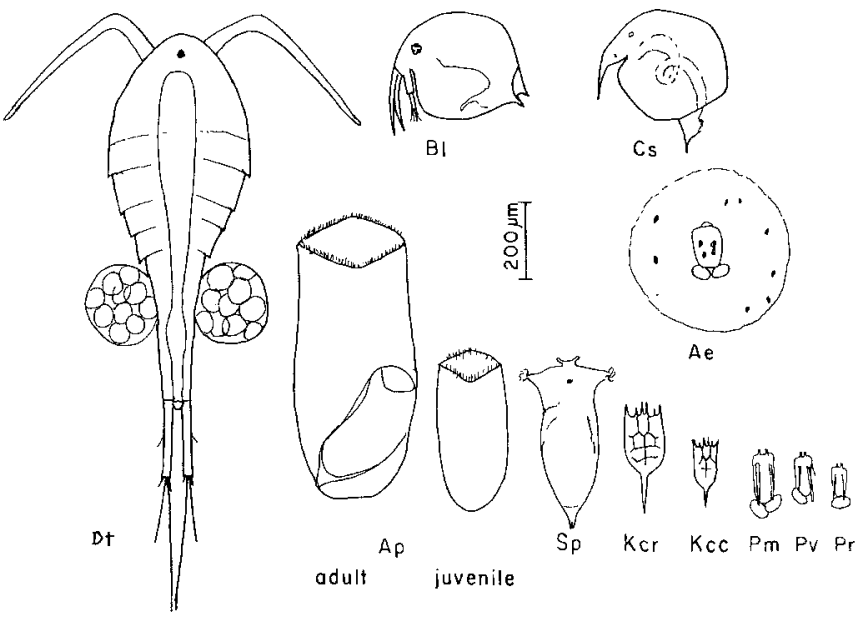

Fig. 1. Zooplankton used in experiments. $\mathrm{Dt}=$ Diacyclops thomasi; $\mathrm{Ap}=$ Asplanchna priodonta $; \mathrm{Sp}=$ Synchaeta pectinata $; \mathrm{Kcr}=$ Keratella crassa $; \mathrm{Kcc}=K$. cochlearis $; \mathrm{Pm}=$ Polyarthra major $\mathrm{Pv}=P$. vulgaris $; \mathrm{Pr}=P$. remata $; \mathrm{Ae}=$ Ascomorpha ecaudis $; \mathrm{Bl}=$ Bosmina longirostris; and $\mathrm{Cs}=$ Chydorus sphaericus

$5 \mathrm{~km}$ offshore from St. Joseph, Michigan with a $0.5-\mathrm{m}$, $150 \mu \mathrm{m}$ mesh net. The copepods were maintained in a $20-\mathrm{L}$ aquarium at $8^{\circ} \mathrm{C}$ with a single cool-white fluorescent light on a 14:10 LD cycle and fed Synchaeta pectinata prey. Synchaeta pectinata, Keratella cochlearis f. typica, K. crassa, Ascomorpha ecaudis, Polyarthra vulgaris, $P$. major, $P$. remata and Asplanchna priodonta were cultured in inorganic MBL medium (Nichols 1973) and fed either Cryptomonas erosa v. reflexa or Rhodomonas minuta (Stemberger 1981). The rotifers listed above and the cladocerans, Bosmina longirostris and Chydorus sphaericus (Fig. 1), were isolated from Lake Michigan and from lakes and ponds in the vicinity of Ann Arbor, Michigan. The cladocerans were reared in 12-L aquaria in Lake Michigan water. Every 3 days Cryptomonas and Rhodomonas were added sparingly.

Prior to experiments, Diacyclops were removed from the aquarium with a sieve and poured into a $25-\mathrm{ml}$ glass dish. Gravid Diacyclops females were removed with a $2-\mathrm{mm}$ wide, glass pipette fitted with a suction bulb and about 30 females were placed into a $500-\mathrm{ml}$, wide-mouth beaker with medium. Synchaeta pectinata was added to yield a density of approximately $700 / \mathrm{L}$. The beaker was placed in the incubator $\left(16^{\circ} \mathrm{C}\right)$ for 3-4 days under a 14:10 LD cycle. This procedure maintained Diacyclops in a sated condition and acclimated them to the experimental temperature $\left(16^{\circ} \mathrm{C}\right)$.

In any one experiment, the volume of medium in each of three experimental beakers $(150-\mathrm{ml})$ was adjusted to $100 \mathrm{ml}$ after adding prey and 2 to 6 Diacyclops. These beakers and 3 similarly treated controls without Diacyclops were placed in the dark at $16^{\circ} \mathrm{C}$ for a predetermined length of time $(<17 \mathrm{~h})$ depending upon the experimental design. At the end of these experiments, the medium was reduced by filtration to $15 \mathrm{ml}$ and Diacyclops were removed. The remaining prey were counted under 50 magnifications of a stereomicroscope and then discarded using a mouthpipette.

Clearance rates ( $\mathrm{ml}$ Diacyclops $\mathrm{s}^{-1} \mathrm{~h}^{-1}$ ) were calculated after Gauld (1951). When predator size, temperature and hunger condition are defined, changes in clearance rates provide a convenient measure of feeding behavior as well as a useful measure of relative prey vulnerability. These rates reflect a predator's ability to harvest different prey. High clearance rates on a prey indicates vulnerability to the predator. Conversely, low clearance rates reflect the prey's ability to interrupt the predation sequence. An electivity index $\left(W_{i}\right)$ was calculated from standardized clearance rates after Vanderploeg and Scavia (1979). This index ranges from a value of 0 (no selection) to 1 (maximum selection) and provides a density-independent measure of selection.

Specific experiments tested Diacyclops selectivity for various rotifer and crustacean prey. In one series of experiments, sated Diacyclops were presented two prey choices at 1:1 proportions and a total density of either 300 or $500 \mathrm{prey} / \mathrm{L}$. In these experiments, Synchaeta was used as a reference prey for six 2-choice combinations with 6 different species of rotifers. Similarly, Diacyclops which had been starved for $20 \mathrm{~h}$ and $48 \mathrm{~h}$ were presented several 2-prey combinations ( $K$. cochlearis or $K$. crassa vs. Synchaeta and $K$. cochlearis vs. $K$. crassa). These experiments tested the effect of predator hunger on selection. In another series of experiments, sated Diacyclops were offered a choice of $S$. pectinata and $K$. cochlearis at different ratios $(10: 90$, $50: 50,90: 10)$ and a constant total density (500 prey/L).

Finally, a series of selection experiments was designed to test selectivity of sated Diacyclops when presented 3 to 8 prey species simultaneously. These experiments were designed in the same manner as 2-prey choice experiments except that variable prey ratios were used. Student's t-tests for paired comparisons were applied to 2-prey choice experiments and one-way analyses of variance were done on multiple prey choice experiments. All experimental results were corrected for control treatments before applying the above statistical tests to the treatment means.

\section{Results}

Prey selection was assessed by comparing clearance rates of Diacyclops and electivity values with Synchaeta as the standard reference prey. Even when starved, Diacyclops selected Synchaeta over Keratella when presented a 1:1 ratio of these species (500 total prey/L) (Table 1). If sated Diacyclops were presented with only predator-resistant prey, $K$. cochlearis or $K$. crassa, the clearance rate on the former was about $13 \%$ of that on Synchaeta. Keratella crassa was not eaten at all. However, 48-h starved Diacyclops consumed some $K$. crassa. Although 20 -h starved Diacyclops selected $K$. cochlearis over the larger $K$. crassa, the clearance rate on the former was only $15 \%$ of the rate for Synchaeta (Table 1). Starved Diacyclops moderately increased clearance rates on these prey over sated individuals (Table 1).

Sated Diacyclops which were offered different species of Polyarthra demonstrated very different selectivites (Table 2). Polyarthra vulgaris was least vulnerable to Diacyclops predation. Clearance rates on $P$. remata and $S y n$ chaeta were similar when these species were offered together but $P$. major was consistently preferred over Synchaeta. In contrast, Diacyclops did not select for the soft-bodied, Ascomorpha ecaudis. Mean clearance rates were approximately $6 \%$ of the rates for Synchaeta. Diacyclops may be repelled after contacting the mucus coating (Stemberger, personal observation).

Sated Diacyclops, which were offered Synchaeta, P. vulgaris and $P$. major simultaneously (Table 3 ), selected $P$. ma- 
Table 1. Summary of 2-choice selection trials for Diacyclops (Dt). $\mathrm{Sp}=$ Synchaeta pectinata $; \mathrm{Kcc}=$ Keratella cochlearis $; \mathrm{Kcr}=K$ crassa. $\mathrm{F}=$ mean clearance rate $\left(\mathrm{ml} \mathrm{Dt}^{-1} \mathrm{~h}^{-1}\right) . \mathrm{SE}=$ standard error for 3 experimental replicates. $W_{i}=$ electivity index. $N_{i}=$ initial prey density of treatments. $\mathrm{N}_{\mathrm{f}}=$ mean final prey density of treatments. $\mathrm{N}_{\mathrm{c}}=$ mean final prey density of controls. $\mathrm{H}=$ Length of experiment (h). Volume of experiments $=100 \mathrm{ml}$

\begin{tabular}{|c|c|c|c|c|c|c|c|c|}
\hline \multirow{3}{*}{$\begin{array}{l}\text { Dt/trial } \\
\text { Prey }\end{array}$} & \multirow[t]{2}{*}{ sated } & \multicolumn{3}{|c|}{ starved } & sated & \multicolumn{3}{|c|}{$\begin{array}{l}\text { starved } \\
\mathrm{h}\end{array}$} \\
\hline & & 4 & & 4 & & 4 & & 4 \\
\hline & $\mathrm{Sp}$ & $\mathrm{Kcc}$ & $\mathrm{Sp}$ & $\mathrm{Kcc}$ & $\mathrm{Kcc}$ & $\mathrm{Kcr}$ & $\mathrm{Kcc}$ & $\mathrm{Kcr}$ \\
\hline $\mathrm{N}_{\mathrm{i}}$ & 25 & 25 & 25 & 25 & 25 & 25 & 25 & 25 \\
\hline $\mathrm{N}_{\mathrm{c}}$ & 25.30 & 23.0 & 25.0 & 23.0 & 24.0 & 25.0 & 24.0 & 24.0 \\
\hline$N_{f}$ & 6.67 & 22.3 & 15.0 & 22.5 & 22.0 & 25.0 & 18.33 & 22.33 \\
\hline $\mathrm{F}^{\mathrm{r}}$ & 4.38 & $0.10^{\mathrm{a}}$ & 6.38 & $0.28^{\mathrm{a}}$ & 0.66 & $0.0^{\mathrm{a}}$ & 1.12 & $0.30^{\mathrm{a}}$ \\
\hline SE & 1.37 & 0.12 & 0.83 & 0.33 & 0.39 & 0.0 & 0.39 & 0.16 \\
\hline$W_{i}$ & 0.98 & 0.02 & 0.96 & $5 \quad 0.04$ & 1.00 & 0.00 & 0.79 & 0.21 \\
\hline $\mathrm{H}^{1}$ & & 7.6 & & 2.0 & & 4.0 & & 6.0 \\
\hline
\end{tabular}

a The null hypothesis that clearance rates are the same for 2-choice trials is rejected at $P=0.05$

Table 2. Summary of 2-choice selectivity trials for Diacyclops (Dt). $\mathrm{Pv}=$ Polyarthra vulgaris $; \mathrm{Pr}=P$. remata $; \mathrm{Pm}=P$. major $;$ and $\mathrm{Ae}=$ Ascomorpha ecaudis. Explanation and symbols as in Table 1

\begin{tabular}{lll|ll|lll|ll}
\hline & sated & \multicolumn{3}{c}{ sated } & \multicolumn{3}{c}{ sated } & \multicolumn{3}{c}{ sated } \\
\hline Dt/trial & & 3 & & 4 & & 2 & & 4 \\
Prey & $\mathrm{Sp}$ & $\mathrm{Pv}$ & $\mathrm{Sp}$ & $\mathrm{Pr}$ & $\mathrm{Sp}$ & $\mathrm{Pm}$ & $\mathrm{Sp}$ & $\mathrm{Ae}$ \\
\hline $\mathrm{N}_{\mathrm{i}}$ & 15 & 15 & 15 & 15 & 15 & 15 & 15 & 15 \\
$\mathrm{~N}_{\mathrm{c}}$ & 15 & 15 & 17 & 15 & 15 & 15 & 16 & 15 \\
$\mathrm{~N}_{\mathrm{f}}$ & 1.13 & 11.67 & 7.67 & 8.67 & 12.33 & 9.0 & 3.33 & 13.66 \\
$\mathrm{~F}$ & 4.36 & $0.42^{\mathrm{a}}$ & 1.69 & 1.16 & 1.35 & $3.67^{\mathrm{a}}$ & 3.88 & $0.23^{\mathrm{a}}$ \\
$\mathrm{SE}$ & 0.59 & 0.3 & 0.60 & 0.93 & 0.59 & 1.65 & 1.36 & 0.12 \\
$\mathrm{~W}_{\mathrm{i}}$ & 0.91 & 0.09 & 0.59 & 0.41 & 0.28 & 0.72 & 0.94 & 0.06 \\
$\mathrm{H}$ & & 10.8 & & 11.8 & & 7.4 & & 10.3 \\
\hline
\end{tabular}

Table 3. Summary of multispecies selectivity trials for Diacyclops (Dt). $\mathrm{Ap}=$ Asplanchna priodonta $; \mathrm{Sp}=$ Synchaeta pectinata $; \mathrm{Pr}=$ Polyarthra remata; $\mathrm{Pv}=P$. vulgaris $; \mathrm{Pm}=P$. major $; \mathrm{Kcc}=$ Kera tella cochlearis $: \mathrm{Kcr}=K$. crassa $; \mathrm{Ae}=$ Ascomorpha ecaudis $; \mathrm{Bl}=$ Bosmina longirostris

\begin{tabular}{|c|c|c|c|c|c|c|c|c|}
\hline \multirow{3}{*}{$\begin{array}{l}\text { Dt/trial } \\
\text { Prey }\end{array}$} & \multicolumn{3}{|l|}{ sated } & \multicolumn{5}{|l|}{ sated } \\
\hline & & 3 & & & & 4 & & \\
\hline & $\mathrm{Sp}$ & $\mathrm{Pv}$ & $\mathrm{Pm}$ & $\mathrm{Sp}$ & Ap & Kcr & $\mathrm{Kcc}$ & $\mathrm{Bl}$ \\
\hline $\mathrm{N}_{i}$ & 10 & 10 & 10 & 10 & 10 & 10 & 10 & 10 \\
\hline $\mathrm{N}_{\mathrm{c}}$ & 10.0 & 9.0 & 9.0 & 11.5 & 13.5 & 10.0 & 8.0 & 8.5 \\
\hline $\mathrm{N}_{\mathrm{f}}^{\mathrm{c}}$ & 8.3 & 8.6 & 3.0 & 1.7 & 11.0 & 9.7 & 6.7 & 7.0 \\
\hline F & 0.83 & 0.20 & $4.88^{\mathrm{a}}$ & $3.01^{\mathrm{a}}$ & 0.32 & 0.05 & 0.27 & 0.30 \\
\hline SE & 0.25 & 0.29 & 1.95 & 1.1 & 0.12 & 0.04 & 0.31 & 0.25 \\
\hline $\mathrm{W}_{\mathrm{i}}$ & 0.15 & 0.03 & 0.83 & 0.76 & 0.08 & 0.01 & 0.07 & 0.08 \\
\hline $\mathrm{H}^{1}$ & & 7.5 & & & & 16.0 & & \\
\hline
\end{tabular}

a The null hypothesis that clearance rates are the same for all prey species is rejected at $P=0.05$. Explanation and symbols as in Table 1
Table 4. Summary of multispecies selectivity trials for Diacyclops (Dt). $\mathrm{Kc}=$ Keratella cochlearis; $\mathrm{Kcr}=K$. crassa; $\mathrm{Pm}=$ Polyarthra major; $\operatorname{Pr}=P$. remata $; \mathrm{Pv}=P$. vulgaris $; \mathrm{Sp}=$ Synchaeta pectinata; $\mathrm{Cs}=$ Chydorus sphaericus $; \mathrm{Ap}=$ Asplanchna priodonta

\begin{tabular}{|c|c|c|c|c|c|c|}
\hline \multirow{3}{*}{$\begin{array}{l}\text { Dt/trial } \\
\text { Prey }\end{array}$} & \multicolumn{6}{|l|}{ sated } \\
\hline & \multicolumn{6}{|l|}{4} \\
\hline & $\mathrm{Sp}$ & $\mathrm{Pv}$ & $\mathrm{Ap}$ & Kcr & $\mathrm{Kcc}$ & Cs \\
\hline$N_{i}$ & 10 & 10 & 10 & 10 & 10 & 10 \\
\hline$N_{c}$ & 10.0 & 10.0 & 16.5 & 10.0 & 8.0 & 10.0 \\
\hline$N_{f}$ & 1.0 & 4.67 & 13.33 & 10.0 & 6.6 & 8.33 \\
\hline $\mathrm{F}$ & $3.7^{\mathrm{a}}$ & 1.27 & 0.34 & 0.0 & 0.32 & 0.3 \\
\hline SE & 0.12 & 0.53 & 0.27 & 0.0 & 0.3 & 0.1 \\
\hline$W_{i}$ & 0.62 & 0.22 & 0.06 & 0.0 & 0.05 & 0.05 \\
\hline $\mathrm{H}$ & & & 15.0 & & & \\
\hline
\end{tabular}

a The null hypothesis that clearance rates are same for all prey species is rejected at $P=<0.05$. Explanation and symbols as in Table 1

Table 5. Summary of multispecies selectivity trials for Diacyclops $(\mathrm{Dt}) . \mathrm{Kcc}=$ Keratella cochlearis $; \mathrm{Ap}=$ Asplanchna priodonta $; \mathrm{Pv}=$ $P$. vulgaris $; \mathrm{Sp}=$ Synchaeta pectinata $; \mathrm{Ae}=$ Ascomorpha ecaudis

\begin{tabular}{|c|c|c|c|c|c|}
\hline \multirow{3}{*}{$\begin{array}{l}\text { Dt/trial } \\
\text { Prey }\end{array}$} & \multicolumn{5}{|l|}{ sated } \\
\hline & 4 & & & & \\
\hline & $\mathrm{Sp}$ & $\mathrm{Pv}$ & $\mathrm{Kcc}$ & $A p$ & $\mathrm{Ae}$ \\
\hline$N_{i}$ & 15 & 15 & 15 & 5 & 5 \\
\hline $\mathrm{N}_{\mathrm{c}}$ & 17.0 & 15.0 & 15.0 & 6.0 & 5.0 \\
\hline$N_{f}$ & 5.0 & 12.33 & 11.33 & 5.7 & 5.0 \\
\hline $\mathrm{F}^{1}$ & $2.4^{\mathrm{a}}$ & 0.38 & 0.55 & 0.10 & 0.0 \\
\hline $\mathrm{SE}$ & 0.05 & 0.19 & 0.09 & 0.16 & 0.0 \\
\hline $\mathrm{W}_{\mathrm{i}}$ & 0.71 & 0.1 & 0.16 & 0.03 & 0.0 \\
\hline $\mathrm{H}^{2}$ & & & 17.0 & & \\
\hline
\end{tabular}

a The null hypothesis that clearance rates are same for all prey species is rejected at $P=0.05$. Explanation and symbols as in Table 1

jor over Synchaeta. The rates on $P$. major were about 6 and 24 times those on Synchaeta and P. vulgaris, respectively. These results further support the strong selection that Diacyclops shows for this species.

In multiple prey choice experiments, the relative selectivities for prey were consistent with results from 2-choice trials (Tables 1-5). Small Bosmina and Chydorus were about as resistant to predation by Diacyclops as Keratella, Asplanchna, and Ascomorpha. Synchaeta was the most highly selected prey in all trials without $P$. major. Ascomorpha and $K$. crassa were the least preferred rotifers. Asplanchna adults were relatively free from Diacyclops predation. However, newborn Asplanchna, which are about the size of Synchaeta, were vulnerable to predation. Significant reproduction in Asplanchna occurred in these experiments as is evident from the increased numbers in the control treatments (Table 4). Thus, size-selective predation on newborn Asplanchna may have artificially increased the clearance rates on this species (Table 4).

Diacyclops selected $S$. pectinata over $K$. cochlearis in all trial proportions with constant density ( 500 prey/L) of these two species (Table 6). At the highest Synchaeta pro- 
portion (90:10), predation on Keratella was not detected. Clearance rates on the former were reduced by a factor of 5 in trials having lower proportions of Synchaeta.

\section{Discussion}

Selectivity by Diacyclops on rotifers is species-specific and could not easily have been predicted based only on prey size, shape, or behavioral response. These results have important implications for the effects of predation by Diacyclops on community structure of rotifers. The mechanism of selection has not been the primary focus of this study. However, analyses of results in the light of laboratory observations provide more insight into specific predator-prey outcomes.

Synchaeta and Keratella have similar swimming speeds $(0.82$ and $0.50 \mathrm{~mm} / \mathrm{s})$ and therefore contribute about equally to encounter rates with Diacyclops (Gerritsen and Strickler 1977; Stemberger, unpublished). Upon contacting Diacyclops, Synchaeta contracts into a sphere and slowly sinks. Diacyclops usually lunges quickly toward the prey and captures it with its grasping mouthparts. Within 30-90 s, Diacyclops ingests the prey completely. When Keratella encounters Diacyclops, it retracts its ciliated corona into the lorica and also passively sinks. Although Keratella is easily captured, the spiny lorica inhibits handling and perhaps ingestion by Diacyclops as well. The presence of the posterior spine in Keratella confers considerable resistance to predation by small copepods (Stemberger and Gilbert 1984). Successfully eaten prey have portions of the lorica bitten off or have the ventral plate torn away from the dorsal plate. Injured and killed Keratella frequently have puncture wounds through the lorica inflicted by the stoutly spined, feeding appendages of Diacyclops. Gilbert and Williamson (1978) report that Mesocyclops may spend up to $30 \mathrm{~min}$ on Keratella [crassa] before releasing it unharmed. The stiff, well-developed lorica of this species may confer a substantial increase in predation resistance over $K$. cochlearis.

Predator hunger increases the clearance rates on both vulnerable and predator-resistant prey (Table 1). Hunger probably increases encounter rates by directly increasing predator swimming speeds or possibly by decreasing the time to complete some or all steps of the predation sequence. In 2-choice selection experiments (Table 1), electivity did not change with hunger if vulnerable prey were available. However, clearance rates on vulnerable prey were notably higher with increased hunger (Table $1, P<0.05$ ). If Diacyclops is offered only predator-resistant prey, it consumes the more vulnerable prey ( $K$. cochlearis) at higher clearance rates than it does if Synchaeta are present (Table 1). Therefore, the hunger state of the predator has a significant effect on both clearance rates and prey selectivity. However, the effect of predator hunger on mortality of resistant prey remains considerably less than for susceptible prey.

The small, soft-bodied Ascomorpha ecaudis are rarely eaten by Diacyclops (Tables 2, 5). Upon contacting the mucus sheath, Diacyclops stops swimming and makes rapid movements with its feeding appendages, apparently attempting to remove adhering mucus. After several encounters with these sheaths, Diacyclops actively avoids them. The mucus confers predation-resistance to Ascomorpha through a taste or textural quality which Diacyclops avoids. Predation on Ascomorpha may occur when the adult swims out of its sheath. However, I never observed predation on this species. Ascomorpha lays eggs which hatch within the mucus cavity. The young remain there for several days before they leave the mothers' mucus envelope. Therefore, they receive maternal protection during a portion, if not all, of their pre-reproductive life. Zooxanthellae, which live in the hypodermis and body cavity of this species (de Beauchamp 1932), may possibly produce, or assist in producing these secretions. Ascomorpha can quickly secrete copius amounts of mucus if it is rapidly stripped away from the rotifer (Stemberger, unpublished). These selection experiments provide the first evidence supporting an antipredatory function of mucus in Ascomorpha. Mucus envelopes are common to a variety of planktonic rotifers including Conochiloides and Collotheca and may also have an anti-predatory function. Mucus also may reduce swimming costs by helping the rotifer to maintain position in the water column (Stemberger and Gilbert, in press).

The selectivity of Diacyclops for Polyarthra was speciesspecific (Tables 2, 3). Gilbert and Williamson (1978) report that $P$. vulgaris is susceptible to predation by the copepod Mesocyclops edax and Brandl and Fernando (1978) report that Cyclops vicinus and $M$. edax select for $P$. dolichoptera and P. major, respectively. In the Laurentian Great Lakes, $D$. thomasi is the dominant copepod predator (Gannon 1972 ) and coexists in space and time with $P$. vulgaris, a dominant rotifer (Stemberger 1974; Nauwerck 1978; Stemberger et al. 1979; Stemberger and Evans 1984). Polyarthra vulgaris was the least vulnerable rotifer in this genus to predation by $D$. thomasi. However, the larger P. major was the most preferred species of all rotifers tested (Table 2, 3). Apparently, Diacyclops easily captures $P$. major as suggested by the ease with which this species can be pipetted in contrast to $P$. vulgaris and $P$. remata (Stemberger, personal observation). Thus, resistance may be related to the speed of the escape response.

A possible explanation for the much higher clearance rates (a factor of 2 or 3) for P. major than for Synchaeta may be related to the hunger condition of Diacyclops. Given that both rotifer species encounter Diacyclops at about equal rates and that Synchaeta also is easily captured and consumed, the high electivity that Diacyclops shows for $P$. major may result from satiation. It takes approximately $1 \mathrm{~h}$ for a sated Diacyclops to evacuate enough space to equal the volume of one Synchaeta (Stemberger, unpublished). Because Polyarthra is about 1/6 the volume of Synchaeta, it would require only about $10 \mathrm{~min}$ to create sufficient gut space for this small prey. Thus, if Diacyclops fed to maintain a full gut, it would have to reject, or partially consume, prey that were larger than the available gut space. Sated Diacyclops will partially consume large Synchaeta in the absence of small, vulnerable prey (Stemberger, unpublished). This behavior is analogous to wasteful killing in insect predators (Holling 1966; Johnson et al. 1975). Therefore, at satiating prey densities, Diacyclops may favor smaller prey. However, other plausible explanations may be found in the specific, predator-prey interaction. For example, $P$. major may be more easily detected by Diacyclops than Synchaeta, thus favoring its predation over Synchaeta. However, this explanation seems unlikely because $P$. major is much smaller than Synchaeta. On the other hand, these results also could be explained if the handling time for Synchaeta was much greater than for Polyarthra. 
Table 6. The effect of constant density (500 prey/L) and variable ratios of vulnerable to resistant prey (Synchaeta pectinata: Keratella cochlearis) on Diacyclops (Dt) selection. $+=$ the null hypothesis that clearance rates are the same among the 3 treatment ratios is rejected at $P=0.05$

\begin{tabular}{|c|c|c|c|c|c|c|}
\hline & \multicolumn{6}{|c|}{ Synchaeta: Keratella } \\
\hline & \multicolumn{2}{|l|}{$10: 90$} & \multicolumn{2}{|l|}{$50: 50$} & \multicolumn{2}{|c|}{$90: 10^{+}$} \\
\hline $\mathrm{Dt} /$ trial & 3 & & 4 & & 4 & \\
\hline Prey & $\mathrm{Sp}$ & $\mathrm{Kcc}$ & $\mathrm{Sp}$ & $\mathrm{Kcc}$ & $\mathrm{Sp}$ & $\mathrm{Kcc}$ \\
\hline $\mathrm{N}_{\mathrm{i}}$ & 5 & 45 & 25 & 25 & 45 & 5 \\
\hline $\mathrm{N}_{\mathrm{c}}{ }^{2}$ & 5.0 & 45.0 & 25.3 & 23.0 & 45.0 & 5.0 \\
\hline $\mathrm{N}_{\mathrm{f}}$ & 3.33 & 41.33 & 6.67 & 22.33 & 36.67 & 5.0 \\
\hline$F^{r}$ & 2.31 & $0.47^{\mathrm{a}}$ & 4.38 & $0.10^{\mathrm{a}}$ & 0.75 & $0.0^{\mathrm{a}}$ \\
\hline SE & 0.75 & 0.23 & 1.37 & 0.12 & 0.28 & 0.0 \\
\hline $\mathrm{W}_{i}$ & $0.83 *$ & 0.17 & 0.98 & 0.02 & 1.0 & 0.0 \\
\hline $\mathrm{H}$ & & 6.0 & & 7.6 & & 6.9 \\
\hline
\end{tabular}

a The null hypothesis that clearance rates are the same for 2-choice trials is rejected at $P=0.05$. Explanation and symbols as in Table 1

This interpretation is not consistent with the observation that Diacyclops easily captures and rapidly consumes Synchaeta. Further study and observation are needed to clarify these results.

The results of the multiple prey selection trials (Tables 3-5) are consistent with the outcome of the 2-prey selection trials. Diacyclops selected Synchaeta in all trials without $P$. major. With the exception of $P$. remata, most prey generally were either very resistant or very vulnerable to predation by Diacyclops.

Diacyclops selected Synchaeta over Keratella cochlearis as the relative abundance (proportion) of the former prey increased while keeping total prey density constant (Table 6). These results support optimal foraging in Diacyclops (Pyke et al. 1977). At a ratio 10:90 (Synchaeta: Keratella), Diacyclops encounters Keratella about 9 times more often than Synchaeta. Assuming that Diacyclops detects both prey equally, the increased attack and handling on Keratella at this ratio may lead to greater mortality and consequently to a decrease in selection for Synchaeta. Only about $20 \%$ of dead or injured Keratella were actually consumed by the end of the experiment which attests to the great difficulty that the lorica poses to this small predator.

In conclusion, within the size range of planktonic rotifers tested (90-750 $\mu \mathrm{m}$ body length) neither prey size nor morphology are dependable predictors of a species' vulnerability to predation by Diacyclops. For example, Keratella cochlearis and $K$. crassa are 10 and 3 times smaller by volume than Synchaeta but are at least 6 times more resistant to predation by Diacyclops. The vulnerability of Polyarthra spp. to predation by Diacyclops is species-specific and may be related to the speed of the escape response. Mucus envelopes in Ascomorpha clearly inhibited predation by Diacyclops, although the mechanism may involve more than simple mechanical fouling of the feeding appendages. Such secretions commonly occur among planktonic rotifers. Also, starved Diacyclops may show increased prey-specific clearance rates over sated individuals. Vulnerable prey are relatively more susceptible to changes in feeding behavior due to predator hunger than are resistant prey. However, satiation may cause a shift in prey selection which favors smaller, vulnerable prey. These predator-prey interactions are valuable not only because they identify potentially important food web pathways in the plankton but also because they provide an experimental framework to help interpret seasonal changes in the species structure and composition of aquatic communities (Stemberger and Evans 1984).

Acknowledgments. I wish to thank A.M. Beeton, J.A. Bowers, J.T. Lehman, S.S. Kilham, J.J. Gilbert, C.W. Burns, M. Rodenhouse and two anonymous reviewers for comments which improved the manuscript.

\section{References}

Brandl Z, Fernando CH (1978) Prey selection by the cyclopoid copepods Mesocyclops edax and Cyclops vicinus. Verh Internat Verein Limnol 20:2505-2510

Beachamp PD de (1932) Contribution a l'etude du genre Ascomorpha et des processus digestifs chez les rotiferes. Bull Soc Zool France 57:428-449

Drenner RW, deNoyelles F, Kettle D (1982) Selective impact of filter-feeding gizzard shad on zooplankton community structure. Limnol Oceanogr 27:965-968

Duncan A (1983) The composition, density and distribution of the zooplankton in Parakrama Samudra. In: Schiemer F (ed) Limnology of Parakrama Samudra-Sri Lanka: a case study of an ancient man-made lake in the tropics. Dr. W. Junk, The Hague, pp 85-94

Duncan A (1984) Assessment of factors influencing the composition, body size and turnover rate of zooplankton in Parakrama Samudra, an irrigation reservoir in Sri Lanka. Hydrobiol $113: 201-215$

Gannon JE (1972) A contribution to the ecology of zooplankton Crustacea of Lake Michigan and Green Bay. PhD Dissertation, University of Wisconsin-Madison

Gauld DT (1951) The grazing rate of planktonic copepods. J Mar Biol Assoc UK 29:695-706

Gerritsen J, Strickler JR (1977) Encounter probabilities and community structure in zooplankton: A mathematical model. J Fish Res Bd Can 34:73-82

Gilbert JJ, Williamson CE (1978) Predator-prey behavior and its effect on rotifer survival in associations of Mesocyclops edax, Asplanchna girodi, Polyarthra vulgaris, and Keratella cochlearis. Oecologia 37:13-22

Holling CS (1966) The functional response of invertebrate predators to prey density. Mem Ent Soc Can 48:1-86

Hrbáček J (1962) Species composition and the amount of zooplankton in relation to the fish stocks. Rozpr Crsk Akad Ved 72:1-116

Johnson DM, Akre BG, Crowley PH (1975) Modeling arthropod predation: wastefull killing by damselfly naiads. Ecol 56:1081-1093

Kerfoot WC (1977) Implications of copepod predation. Limnol Oceanogr 22:316-325

Kerfoot WC (1978) Combat between predatory copepods and their prey: Cyclops, Epischura and Bosmina. Limnol Oceanogr 23:1089-1102

Kerfoot WC (1982) A question of taste : crypsis and warning coloration in freshwater zooplankton communities. Ecol 63:538-554

Lewis WM Jr (1977) Feeding selectivity of a tropical Chaoborus population. Freshwat Biol 7:311-325

Li JL, Li HW (1979) Species-specific factors affecting predatorprey interactions of the copepod Acathocyclops vernalis with its natural prey. Limnol Occanogr 24:613-626

Nauwerck A (1978) Notes on the planktonic rotifers of Lake Ontario. Arch Hydrobiol 84:269-301

Nichols HW (1973) Growth media-freshwater. In: Stein JR (ed) Handbook of Phycological Methods Cambridge University Press, New York, pp 7-24 
Norden CR (1968) Morphology and food habits of the larval alewife, Alosa pseudoharengus (Wilson), in Lake Michigan. Proc 11 th Conf Great Lakes Res Internat Assoc Great Lakes Res 1968:103-110

O'Brien WJ (1979) The predator-prey interaction of planktivorous fish and zooplankton. Amer Sci 67:572-581

O'Brien WJ, Kette D, Riessen HP (1979) Helmets and invisible armor: structures reducing predation from tactile and visual planktivores. Ecol 60:287-294

Pastorok RA (1980) The effects of predator hunger and food abundance on prey selection by Chaoborus larvae. Limnol Oceanogr 25:910-920

Pastorok, RA (1981) Prey vulnerability and size selection by Chaoborus larvae. Ecol 62:1311-1324

Pyke GH, Pulliam HR, Charnov EL (1977) Optimal foraging: a selective review of theory and tests. Quart Rev Biol 52:137-154

Riessen HP (1980) Diel vertical migration of pelagic water mites. In: Kerfoot WC (ed) The evolution and ecology of zooplankton communities. Univ Press of New England, pp 129-137

Siefert RE (1972) First food of larval yellow perch, bluegill, emerald shiner and rainbow smelt. Trans Am Fish Soc 101:219-225

Stemberger RS (1974) Temporal and spatial distributions of planktonic rotifers in Milwaukee Harbor and adjacent Lake Michigan. Proc 17th Conf Great Lakes Res, Internat Assoc Great Lakes Res, pp 120-134

Stemberger RS (1981) A general approach to the culture of planktonic rotifers. Can J Fish Aquat Sci 38: 721-724
Stemberger RS, Evans MS (1984) Rotifer seasonal succession and copepod predation in Lake Michigan. J Great Lakes Res $10: 417-428$

Stemberger RS, Gilbert JJ (1984) Spine development in the rotifer Keratella cochlearis: induction by cyclopoid copepods and $A s-$ planchna. Freshwat Biol, in press

Stemberger RS, Gilbert JJ Body size, food concentration and population growth in planktonic rotifers. Ecol (in press)

Stemberger RS, Gannon JE, Bricker FJ (1979) Spacial and seasonal structure of rotifer communities in Lake Huron. EPA-600/3-79085

Vanderploeg HA, Scavia $D(1979)$ Two electivity indices for feeding with special reference to zooplankton grazing. J Fish Res Board Can 36:362-365

Williamson CE (1980) The predatory behavior of Mesocyclops edax: predator preferences, prey defenses, and starvation induced changes. Limnol Oceanogr 25:903-909

Williamson CE (1983) Invertebrate predation on planktonic rotifers. Hydrobiol 104:385-396

Zaret TM (1972) Predators, invisible prey, and the polymorphism in the Cladocera (Class Crustacea). Limnol Oceanogr 17:171-184

Zaret TM, Kerfoot WC (1975) Fish predation on Bosmina longirostris: visibility selection versus body-size selection. Ecol $56: 232-237$

Received April 5, 1984 